\title{
Het zelfbeeld van reclamemakers in de Nederlandse reclamevakpers \\ 1967-1972
}

Over de culturele betekenis van televisiereclame lopen de meningen uiteen. Reclame in het algemeen en televisiereclame in het bijzonder is door cultuurwetenschappers vaak beschouwd als een weinig verheffend verschijnsel. ${ }^{\mathrm{I}}$ Dat neemt niet weg dat reclame een centrale plaats verworven heeft binnen de westerse cultuur van de twintigste eeuw. En dat is een ontwikkeling die volgens de Amerikaanse auteur James Twitchell niet louter negatief is, want reclame voorziet in onze behoefte betekenis te geven aan materiële objecten. ${ }^{2}$

Dit artikel gaat in op de vraag in hoeverre reclamemakers zelf, in de beginperiode van de televisiereclame in Nederland, tv-reclame beschouwden als een vorm van cultuur. In het verlengde daarvan wordt de vraag gesteld wat dit zegt over het beeld dat reclamemakers van hun eigen vak en van hun beroepsgroep hadden. Daarbij baseer ik me op de Nederlandse reclamevakpers. Aan de hand van een analyse van artikelen over de achtergrond en inhoud van televisiecommercials in de Nederlandse reclamevakpers in de periode I967-1972 zal een beeld worden geschetst van de opvattingen van reclamemakers over televisiereclame, en van de rol die zij voor zichzelf weggelegd zagen bij de totstandkoming van televisiecampagnes, inclusief hun culturele rol. Onder reclamemakers worden hier de professionals verstaan die betrokken waren bij het bedenken en uitvoeren van de reclames: de tv-producers, copywriters en art directors die werkzaam waren bij de reclamebureaus, en de producenten en regisseurs die veelal in dienst waren van productiemaatschappijen. ${ }^{3}$

In de geschiedschrijving over de Nederlandse televisie is de aandacht voor televisiereclame tot nu toe beperkt. ${ }^{4}$ Dat geldt ook voor de publicaties over (Nederlandse) reclamegeschiedenis. ${ }^{5}$ De weinige proefschriften over onderwerpen uit de Nederlandse reclamegeschiedenis die tot nu toe verschenen zijn, richten zich op de periode vóór de komst van tv-reclame. ${ }^{6}$ De publicaties die wél over de geschiedenis van tv-reclame gaan, hebben overwegend een populairwetenschappelijk karakter en zijn in hoge mate anekdotisch. ${ }^{7}$ Dit artikel is mede bedoeld als aanzet tot nader wetenschappelijk onderzoek naar de geschiedenis van de reclamebranche in Nederland.

\section{De reclamemaker onder de historische loep}

De belangstelling voor het zelfbeeld van de professionals die werkzaam zijn in de media-industrie lijkt de laatste jaren toe te nemen. Illustratief daarvoor zijn de publicaties van de Amerikaanse hoogleraar Film en Media Studies John T. Caldwell. In zijn in 2008 verschenen boek Production Culture. Industrial Reflexivity and Critical Practice in Film and Television richt Caldwell zich op 'the industry's own self-representation, self-critique, and self-reflection'. Door zich bij 
het onderzoek niet te beperken tot de 'officiële' interviews en perspublicaties die door de mediabedrijven naar buiten worden gebracht, maar ook aandacht te schenken aan debatten die makers onderling voeren, zouden onderzoekers meer en beter inzicht kunnen krijgen in de wijze waarop esthetische beslissingen rondom films en televisieprogramma's tot stand komen en theoretische concepten naar de praktijk worden vertaald. ${ }^{8}$
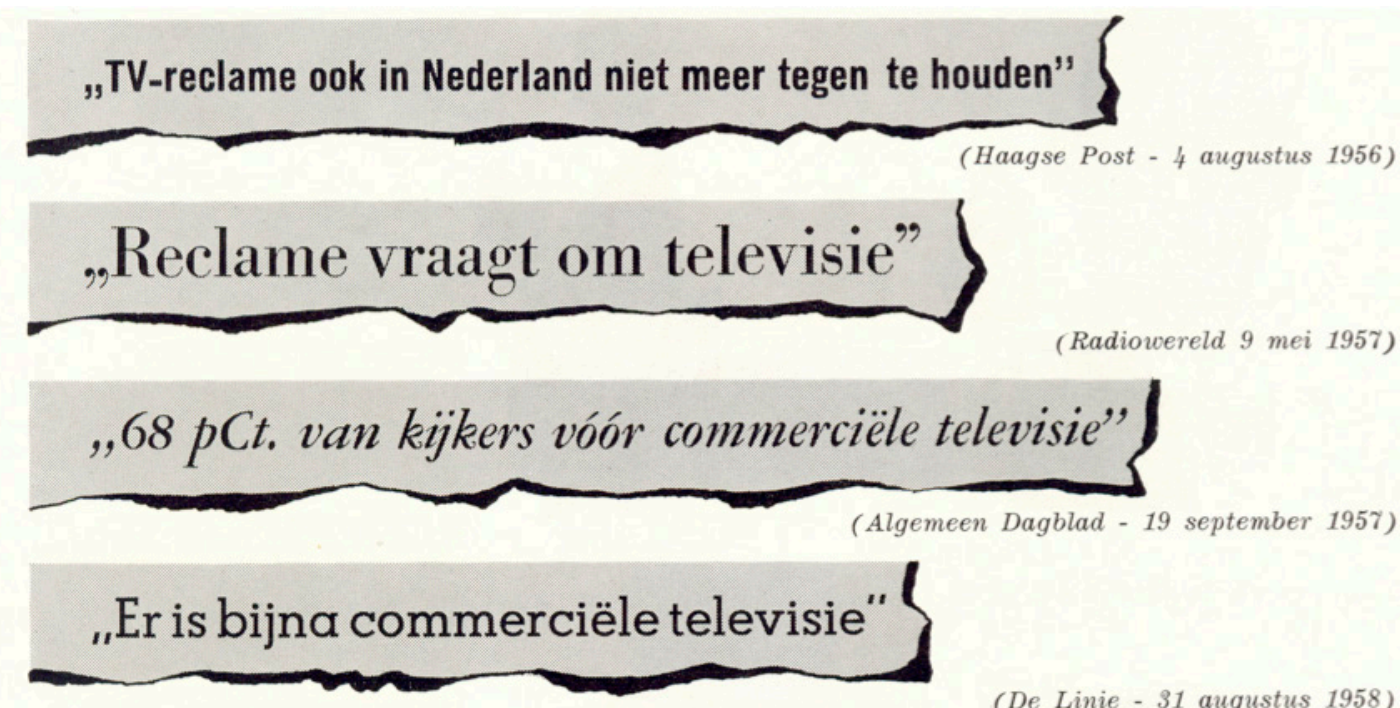

(Radiowereld 9 mei 1957)

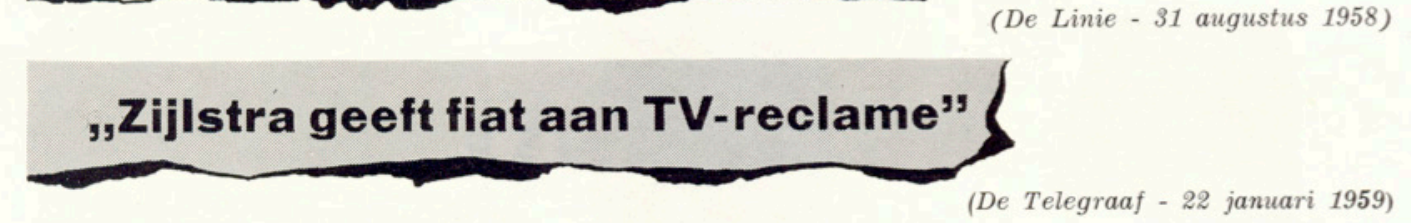

Nog éven .... en vóór $U$ het weet, is de eerste commerciële televisiefilm vertoond.....

Televisie - een medium dat nu voor iedere reclameman interessant gaat worden - een medium dat U niet meer kunt missen.

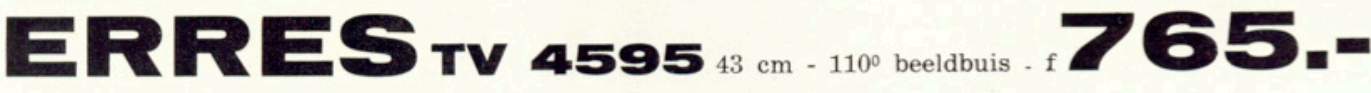 met $53 \mathrm{~cm}$ beeldbuis $\mathrm{f} 945$.}

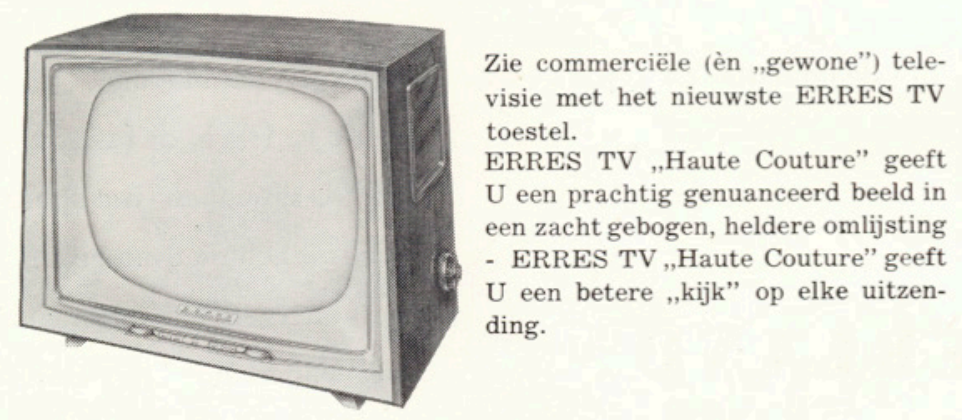

ERRES TELEVISIE aan of uit, een toonbeeld van volmaaktheid See your dealer today R.S. Stokvis' producten, vervaardigd door Van der Heem

Afb. 1 Een advertentie voor Erres-televisie met verwijzingen naar de politieke discussie over de komst van televisiereclame.

Bron: Ariadne, juli 1959. 
Ook de zelf-reflexiviteit van reclamemakers is de laatste decennia door diverse auteurs aan de orde gesteld, met name vanuit historisch perspectief. Zo geeft de Canadese historicus Roland Marchand in zijn veelgeprezen studie Advertising the American Dream. Making Way for Modernity (I985) een schets van de Amerikaanse reclamemakers in de jaren twintig en dertig van de twintigste eeuw. Hij stelt dat zij zichzelf beschouwden als 'missionaries of modernity', die het als hun taak zagen het publiek te verzoenen met de zegeningen van de moderne samenleving, en met de consumptieartikelen die door massaproductie werden vervaardigd. 9 Deze min of meer educatieve taak zou in de tweede helft van de twintigste eeuw naar de achtergrond verdwijnen. Volgens sommige auteurs gingen reclamemakers zichzelf meer en meer zien als onderdeel van de culturele voorhoede van de samenleving. William Leiss, Stephen Kline, Sut Jhally en Jacqueline Botterill wijzen er in Social Communication in Advertising. Consumption in the Mediated Marketplace (2005) op dat vanaf de jaren zestig van de twintigste eeuw binnen de reclamewereld zelf, en met name bij de reclamebureaus die in opdracht van adverteerders de campagnes maakten, steeds meer belang werd gehecht aan het creatieve karakter van de reclame. In het verlengde daarvan legden reclamemakers meer nadruk op reclame als een cultureel fenomeen, en minder op de bedrijfsmatige en economische functie. Die verschuiving zou onder meer blijken uit de waarde die reclamemakers hechten aan de reclameprijzen, de jaarlijkse bekroningen die zij elkaar toekennen voor de meest aansprekende en creatieve campagnes (een voorbeeld daarvan zijn de ADCN-lampen die vanaf ${ }_{9} 967$ in Nederland jaarlijks door jury's van reclamemakers aan vakgenoten worden uitgereikt). Ook het verschijnsel dat in de reclamewereld vanaf de jaren zestig het begrip 'creatief' gebruikt wordt als zelfstandig naamwoord voor de functie van de medewerkers binnen het reclamebureau die de reclamecampagnes bedenken en ontwerpen, zou in die richting wijzen, aldus Leiss et al. "The very act of naming themselves "creatives" shows how advertisers sought to secure cultural privilege'. ${ }^{\text {ro }}$ Daarmee wilden zij afstand nemen van het imago van verkoper dat van oudsher aan hun beroep van reclamemaker kleefde. Het verlangen naar maatschappelijke erkenning en de wens om indruk te maken op vakgenoten en op de artistieke elite, zou er toe hebben geleid dat reclamemakers 'have also attempted to turn their commercial canvas into something more than the crass selling of messages'. Reclamemakers zouden hiermee vallen in de categorie van 'culturele intermediairs'. ${ }^{\text {II }}$

\section{De reclamemaker als cultureel intermediair}

Het begrip culturele intermediair is afkomstig van de Franse socioloog Pierre Bourdieu, die stelde dat de samenleving bestaat uit 'velden' die met elkaar interageren. Het economische en het culturele veld zijn het meest belangrijk; binnen het culturele veld draait het om het vergaren van cultureel kapitaal, dat onder meer door educatie en beroep wordt verworven. Binnen elk veld, en dus ook binnen de cultuur, speelt zich een machtsstrijd af. Onderdeel hiervan is het benadrukken van de culturele waarde van de eigen professionele activiteiten, met de bedoeling cultureel kapitaal te verwerven. De culturele intermediairs zijn afkomstig uit de beroepen waarvan de beoefenaren betrokken zijn bij de productie en verspreiding van goederen en diensten waaraan een bijzondere symbolische waarde wordt gehecht; tot deze categorie rekende Bourdieu onder meer de makers van culturele programma's op radio en tv, de critici van 'kwaliteitskranten' en -tijdschriften, en schrijvers-journalisten. ${ }^{\text {I2 }}$ 
Bourdieu beperkt het begrip tot de eerdergenoemde beroepen. Latere auteurs hebben de reikwijdte van het begrip uitgebreid; de term cultureel intermediair is onder meer gebruikt voor gidsen die in musea werkzaam zijn en voor public relations-officers. ${ }^{\text {I3 }}$ Ook reclamemakers worden tot deze categorie gerekend. Volgens Aidan Kelly, Katrina Lawlor en Stephanie O’Donohoe dienen zij zelfs gezien te worden als uiterst invloedrijke culturele intermediairs. Door in de campagnes die ze maken de nieuwste culturele trends te verwerken, vormen zij een belangrijke schakel tussen de wereld van het bedrijfsleven en die van de cultuur. ${ }^{\mathrm{T} 4}$ De Britse hoogleraar sociologie Mike Featherstone schaart reclamemakers onder de 'nieuwe' culturele intermediairs, de beroepsgroepen die vanaf eind twintigste eeuw een sleutelrol spelen in de esthetisering van het dagelijks leven en zo bijdragen aan het dichten van de aloude kloof tussen hoge en lage cultuur. ${ }^{15}$

Bij het gebruik van het begrip cultureel intermediair voor reclamemakers zijn wel enige kanttekeningen gemaakt. In zijn studie naar de Britse reclame-industrie merkt de Britse hoogleraar reclame, marketing en media Sean Nixon op dat de claims van Featherstone niet of nauwelijks onderbouwd worden door kwantitatieve gegevens, en dat de culturele opmars van de reclamemaker door hem min of meer als een gegeven wordt aangenomen. Volgens Nixon werd er binnen de beroepsgroep zelf geenszins eensluidend gedacht over het culturele belang van reclame. Waar een deel van de Britse reclamemakers in de tweede helft van de twintigste eeuw streefde naar professionalisering en formalisering van het reclamevak, beschouwden anderen hun werk veeleer als artistiek en gericht op creativiteit. ${ }^{16}$ Ook Leiss et al. wijzen erop dat de opvattingen binnen de reclamewereld niet uniform waren. ${ }^{\mathrm{I7}}$ Tegenover de reclamemakers die hun vak vooral zagen als een professie waarin het draaide om creativiteit stonden collega's volgens wie reclame primair gericht diende te zijn op business, oftewel verkoop en commercieel resultaat, en die daarom bij het maken van campagnes onderzoek en ratio voorop stelden. In dit artikel zal ook gekeken worden hoe, en in welke mate, deze tegenstellingen hun weerklank vonden in de opvattingen over televisiereclame en de rol van de reclamemaker in Nederland.

\section{Televisiereclame in Nederland, 1967-1972}

Terwijl in de Verenigde Staten al in de jaren veertig van de twintigste eeuw de eerste tv-commercials te zien waren en in Groot-Brittannië vanaf 1955 tv-reclame werd uitgezonden, duurde het in Nederland tot ${ }^{1} 967$ voordat de eerste reclameblokken op tv werden vertoond. ${ }^{18}$ Deze late opkomst is vooral te verklaren vanuit de politieke situatie. Tv-reclame was in het Nederland van de jaren vijftig en zestig een politiek gevoelig onderwerp, omdat het inbreuk deed op het bestaande omroepbestel. Vanuit verschillende politieke partijen bestond er weerstand tegen de mogelijke invloed vanuit het bedrijfsleven op het televisiebestel, en heerste de angst dat 'reclame in de televisie' zou bijdragen aan een verdere Amerikanisering van de Nederlandse samenleving. In plaats van door adverteerders gesponsorde programma's - zoals ze in de Verenigde Staten aanvankelijk te zien waren - koos de Nederlandse regering voor reclameblokken waarin, op vaste tijdstippen, afzonderlijke reclamefilms, commercials geheten, van diverse adverteerders achter elkaar werden uitgezonden. Men koos daarmee voor het zogenaamde 'Beierse' model, waarbij de reclame deel uitmaakte van het publieke bestel en niet, zoals in Groot-Brittannië, ondergebracht werd bij een zender die een op commerciële leest geschoeide programmering verzorgde. 

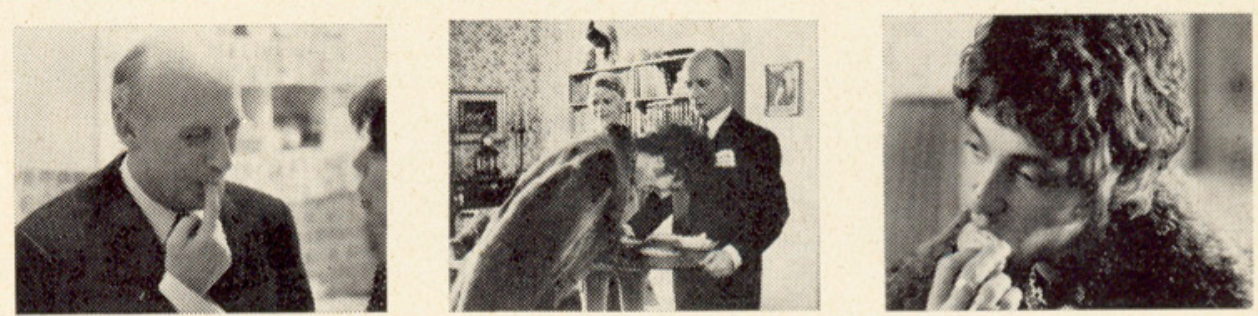

Dipsaus (uitzendingen vanaf maart). Pa en moe in de keuken. Er komt bezoek. Zij maakt het laatste dipsausje klaar. Vader doopt z'n vinger erin. Moeder bestraffend: daar doop je chips in, niet je vingers. Vader met schaal dipsaus de kamer in, waar dochters nieuwe vriend een langharige jongeman blijkt met kettingen. Vriend buigt zich voorover, zijn medaille valt in de dipsaus. Hij likt het af en zegt: hé, tof sausje, weetjedat? Vader: daar doop je chips in, weetjewel!

De vriend werd gespeeld door grimeur Bob Eerhart.
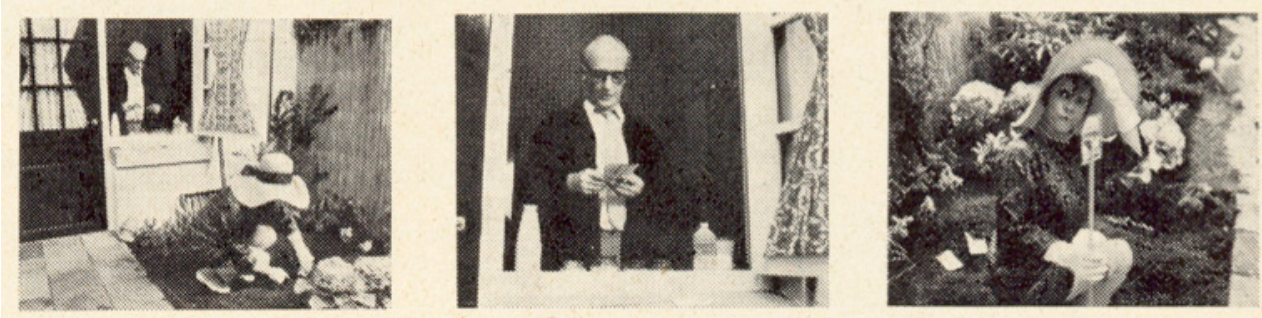

Slamix (uitzendingen vanaf april). Moeder zaait in de tuin, vader staat aan het keukenraam: wat ben je aan 't zaaien? Sla, schat. Vader kijkt op de lege zakjes en realiseert zich dat ze slamix (te mengen met salata) zaait. Hij legt uit wat het is en vraagt smalend: wanneer denk je dat op tafel te zetten? Moeder: als 't opkomt natuurlijk, over een paar maanden.
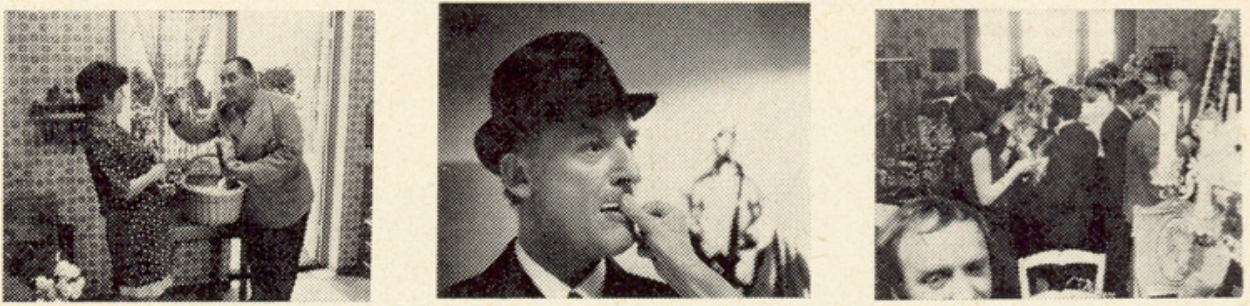

Afb. 2 Stills met bijschriften uit de televisiecampagne voor Duyvis.

Bron: Ariadne, 1970, p. 57.

De hoeveelheid reclame bleef op de Nederlandse televisie in de eerste jaren, gerekend over een hele uitzendavond, beperkt tot enkele blokken rondom de journaals. In totaal kwam het neer op niet meer dan een kwartier tot een half uur aan tv-reclame per avond. ${ }^{19}$ Dit betekent echter niet dat televisiereclame in de reclamevakpers in deze jaren een onderbelicht onderwerp was. De reclamevakbladen vormden een podium waarop vakgenoten met elkaar van gedachten wisselden over de thema's die binnen hun professie speelden, en daar hoorde televisiereclame ook bij. ${ }^{20}$ Voor dit onderzoek zijn de jaargangen I967-I972 van Revue der Reclame en Ariadne geanalyseerd. ${ }^{2 \mathrm{I}}$ Voor deze chronologische afbakening is gekozen omdat in deze periode televisiereclame in Nederland een aanvang nam en het onderwerp in de vakpers hoog op de agenda stond. 


\section{Kinderziektes}

In de geanalyseerde jaargangen van de eerste jaren - de periode van I967 t/m I969 - ging er relatief veel aandacht uit naar de technische kanten van de productie van televisiecommercials. Televisie was als reclamemedium nieuw en dat betekende dat Nederlandse reclamemakers zich het metier eigen moesten maken. De eisen die het medium aan de makers stelde en de valkuilen die zich aandienden bij het maken van commercials, kwamen regelmatig aan bod.

Tijdens een rondetafeldiscussie die in het tweede jaar na de start van de STER (Stichting Ether Reclame) door Revue der Reclame werd georganiseerd, constateerden verschillende betrokkenen uit de reclamewereld dat reclamemakers moeite hadden met het medium televisie. 'In het begin zaten wij weleens te kijken naar films waarvan wij ons na twee-, driemaal nog afvroegen: wat verkóópt die man nu eigenlijk?', merkte Chris Smeekes, adjunct-directeur van de sTER, op. Ook Karel Nort, hoofd televisie-, radio- en filmproductie van reclamebureau Nijgh en Van Ditmar, was kritisch. ' $\mathrm{Na}$ anderhalf jaar televisiereclame worden er nog principiële fouten gemaakt bij de producties. Wij zien commercials die a-synchroon zijn, of waar op ondeskundige wijze van een jingle gebruik is gemaakt'. ${ }^{22}$

Naast de kinderziekten van tv-reclame was in de beginperiode ook de effectiviteit een onderwerp dat aandacht genoot. Televisiereclame diende tenslotte dienstbaar te zijn aan de commerciële doelstellingen van de adverteerder. Bovendien moest tv-reclame zich als marketing-instrument bewijzen ten opzichte van andere media, zoals dagbladen en tijdschriften. Dus lag het voor de hand ook te kijken naar de concrete uitwerking ervan. Er werden diverse artikelen gewijd aan onderzoek, en met name aan het zogenaamde pre-testen: het testen van commercials vóór uitzending op de televisie. ${ }^{23}$ Ook in de bespreking van de commercials die uitgezonden werden, kwam het beoogde effect aan bod. Dat gebeurde bijvoorbeeld in een artikel over de allereerste commercial die bij de STER werd uitgezonden, voor het Cebuco, de organisatie die de collectieve promotie van het medium dagblad verzorgde (Centraal Bureau voor de Courantenpubliciteit, nu NDP Nieuwsmedia). In een toelichting maakte de directeur van het Cebuco duidelijk dat de commercial, die de eerste vormde in een reeks tv-reclames, een belangrijk onderdeel was van de strijd die het bureau wilde leveren tegen televisie als reclamemedium: de commercials moesten duidelijk maken dat, ondanks de opkomst van televisiereclame, de krant voor adverteerders een onmisbaar reclamemedium bleef. ${ }^{24}$

De opvatting dat televisiereclame vooral beoordeeld moest worden op commerciële gronden, klonk in de eerste jaren in tal van artikelen door. Typerend daarvoor is de visie van M. Chanowski, directeur van productiemaatschappij Chanowski Productions. Op de vraag of tv-commercials gebaat zouden zijn bij 'snelle montages', zodat ze 'flitsender' zouden worden, antwoordde hij 'dat bij het uiteindelijke doel van t.v.-reclame de amusementsfactor niet voorop staat en een ogenschijnlijk saaie spot zou wel eens meer verkoopresultaten kunnen hebben dan een virtuoos gemaakt humoristisch filmpje'. Op de vraag voor welke tv-commercials hij waardering had, noemde Chanowski een aantal commercials die 'op verantwoorde wijze een duidelijke boodschap overbrengen', waaronder een commercial voor Maggi-groentesoep waarin het verkoopargument dat het product nu 50 procent meer groente bevatte, centraal stond. ${ }^{25}$

Aan het eind van de jaren zestig werd in diverse artikelen de vraag aan de orde gesteld wanneer televisiereclame als geslaagd kon worden beschouwd. Een van de criteria die daarbij 
werden genoemd, was de mate waarin de mogelijkheden van het medium televisie werden benut. Zo beoordeelde copywriter Christiaan Oerlemans in Revue der Reclame in de jaren I967 en I968 maandelijks recent uitgezonden commercials en daarbij constateerde hij herhaaldelijk dat het zijn collega's moeite kostte het medium goed te benutten, met name in visueel opzicht. Veel van de commercials waren in zijn ogen niet meer dan 'bewegende advertenties'. ${ }^{26}$ Daarmee gaf hij expliciet aan dat goede televisiereclame zich duidelijk van de reclame in kranten en tijdschriften diende te onderscheiden.

Een ander aspect waaraan in de vakpers aandacht werd besteed, was de originaliteit van televisiereclame. Zo schreef Ariadne in I970 uitvoerig over een nieuwe tv-campagne voor het merk Duyvis, waarin het medium tv op een voor reclamebegrippen vernieuwende wijze werd gebruikt. In de in totaal negen commercials die de campagne telde, werden korte verhaaltjes uitgebeeld, die zich afspeelden in een gezin. Deze keuze was volgens de auteur van het artikel mede ontleend aan rond 1970 populaire tv-series als Peyton Place en Coronation Street, waarin het familieleven ook een belangrijk rol speelde. De creative director van het reclamebureau, Harry van den Eerenbeemt, die als scriptschrijver de karakters uitwerkte en de verhaaltjes voor de commercials bedacht, streefde daarbij naar eigen zeggen naar een 'speelfilm-sfeer'. Hij benadrukte vooral het belang van 'authenticiteit' in de commercials; clichés dienden zijns inziens zoveel mogelijk vermeden te worden. ${ }^{27}$ Ook in een tv-campagne voor de Volkswagen Kever werd door de creative director van het reclamebureau dat de campagne verzorgde, Guido Hasselaar, gehamerd op het belang van originaliteit. Voor deze commercials had Hasselaar zich mede gebaseerd op het op dat moment populaire satirische tv-programma HADIMASSA, en, in de stijl van het tv-programma, 'absurde dialoogjes' geschreven, die werden uitgevoerd door de destijds bekende acteurs Henk van Ulsen en Yoka Beretti. Om de commercials ook voor een jongere doelgroep aantrekkelijk te maken, was gekozen voor een benadering die de creative director omschreef als 'anti-snob': een benadering waarbij de Volkswagen Kever werd afgeschilderd als een auto voor mensen die wars waren van pretenties. Bijzonder was volgens Hasselaar dat de reclameboodschap in de commercials volledig afwezig was; daarmee zou er volgens hem sprake zijn van een 'wereldprimeur'. ${ }^{28}$ Zowel voor Hasselaar als voor Van den Eerenbeemt was het streven naar creativiteit een belangrijke overweging bij het maken van televisiereclame.
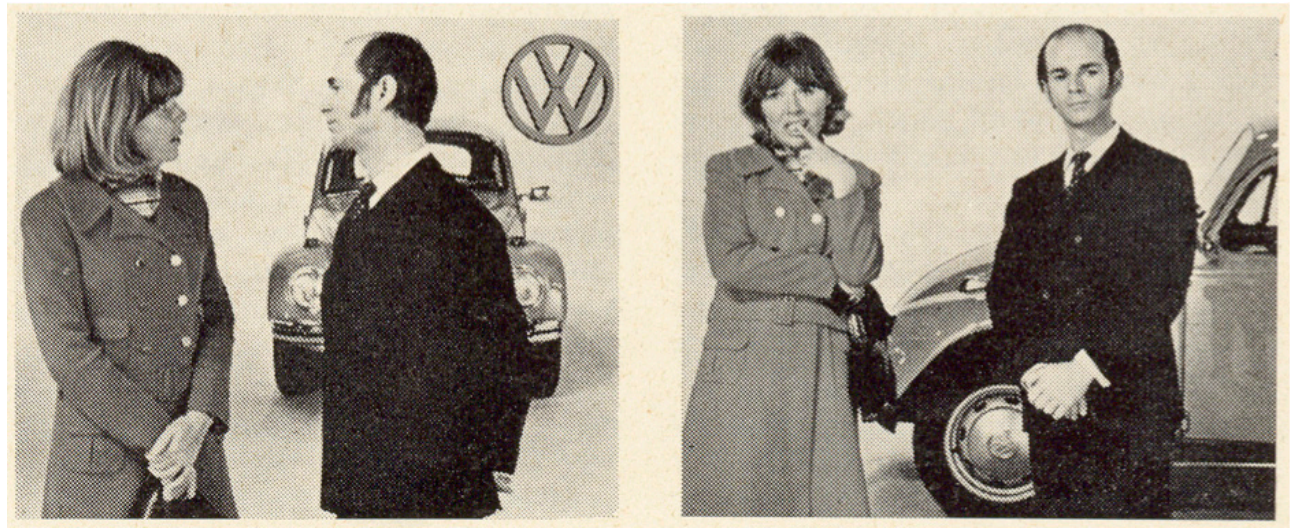

Afb. 3 Stills uit de televisiecampagne voor Volkswagen.

Bron: Revue der Reclame, 1970, p. 179. 


\section{Reclamebureaus versus productiemaatschappijen}

De artikelen in de reclamevakpers getuigen vooral in de beginjaren van de behoefte om reclame te positioneren als economisch en cultureel verschijnsel dat binnen het medialandschap aan bepaalde inhoudelijke en formele criteria voldoet. In het begin van de jaren zeventig begon de aandacht enigszins te verschuiven. In toenemende mate kwamen ook de professionele eisen die aan tv-reclame konden worden gesteld, de vakspecifieke competenties waaraan de reclamemaker moest voldoen en de organisatorische aspecten van het productieproces aan bod.

Deze kwesties kwamen onder meer ter sprake in een aantal artikelen die begin jaren zeventig in de vakpers verschenen over de relatie tussen reclamebureaus en productiemaatschappijen. Dat dit onderwerp de gemoederen in reclameland bezighield, is niet vreemd, want het hing nauw samen met de belangen van beide partijen. Vanaf het moment dat televisiereclame zich in Nederland aandiende, zagen productiemaatschappijen als Toonder Studio's, Geesink Studio, Oscar Film en Top Spot (onderdeel van Carillon Films) deze nieuwe vorm van reclame als een voor hen aantrekkelijk werkterrein. ${ }^{29}$ Productiemaatschappen hadden ervaring met het maken van films in opdracht, en veelal ook met de productie van commercials voor de bioscoop in Nederland en voor televisie in het buitenland. Volgens Bert Kroon waren er rond I970 circa twintig productiemaatschappijen actief op het gebied van de productie van televisiecommercials. ${ }^{3 \circ}$ Van die maatschappijen waren met name Geesink Studio en Toonder internationaal bekend. Uit het boek De Documentaire Film 1945-1965. De bloei van een filmgenre in Nederland (2003) van mediahistoricus Bert Hogenkamp weten we dat er decennialang sprake was van kruisbestuiving tussen de wereld van de (langere) opdrachtfilm en de reclamefilm; vaak waren producenten, regisseurs en scriptschrijvers op beide terreinen actief. ${ }^{31}$ Tegenover de productiemaatschappijen stonden de reclamebureaus, die over het algemeen weinig ervaring hadden met film, maar wel thuis waren in het maken van reclamecampagnes. Voor de bureaus was het van belang hun opdrachtgevers duidelijk te maken dat televisiereclame primair het domein was van het reclamebureau, en niet van de productiemaatschappij.

In de artikelen over de verhouding tussen productiemaatschappijen en reclamebureaus werd onder meer aandacht besteed aan de vraag op welke wijze de makers van televisiereclame hun rol idealiter zouden moeten invullen. De representanten van de reclamebureaus waren van mening dat de reclamemaker creatief onderlegd moest zijn om zijn werk goed te kunnen doen. Volgens Michiel Beishuizen, tv-producer bij reclamebureau Prad, schortte het daar bij de meeste Nederlandse productiemaatschappijen aan. 'Ze leggen de zaak keurig vast op celluloid, maar dat is dan ook alles. Ze hebben geen eigen creatieve inbreng'. ${ }^{32}$ Theo Strengers, adjunct-directeur van reclamebureau Intermarco delaMar, was dezelfde mening toegedaan. 'Ik geloof dat er bij de Nederlandse produktiemaatschappijen grotendeels de juiste mentaliteit ontbreekt. Een bureau verkoopt creativiteit en dat stelt bepaalde eisen aan de medewerkers. Er moet een affectie bestaan voor modeverschijnselen, omwentelingen - communicatie drijft op het tijdsgebeuren.' Een regisseur van tv-commercials diende voeling te hebben met de actuele ontwikkelingen op cultureel gebied, en dat was volgens Strengers bij de medewerkers van productiemaatschappijen in Nederland niet, maar in Engeland wél het geval. 'Ze hebben Butch Cassidy eerder gezien dan jijzelf. Nieuwe ontwikkelingen in mode en muziek kennen ze niet alleen, maar beleven ze ook'.33 
In de ogen van de vertegenwoordigers van de productiemaatschappijen die in de artikelen aan het woord kwamen, getuigden dergelijke opvattingen van weinig realiteitszin. Televisiereclame was voor hen primair een kwestie van het realiseren van de commerciële doelstellingen van de opdrachtgever. 'Alles komt terug bij de vraag: wat is een goeie commercial?', aldus Pieter de Man, directeur van productiemaatschappij Oscar Film. 'Hoe weten we wat de resultaten zijn? Hoe kunnen we vergelijken? Als er getest wordt, kunnen we zeggen: jij bent goed en jij bent slecht.' Bert Kroon, directeur van productiemaatschappij Toonder Studio's, was uiterst nuchter in zijn opvatting over de culturele bagage waarover de makers van televisie- en radioreclame dienden te beschikken. Naar aanleiding van de hierboven geciteerde uitspraak van Strengers merkte hij niet zonder ironie op: 'Vanmorgen op de autoradio - de Witte Reus viert z'n verjaardag. Nu twee grote pakken met een kwartje voordeel. Vier de verjaardag van de Witte Reus mee. Moet je daar Butch Cassidy voor hebben gezien?'. 34

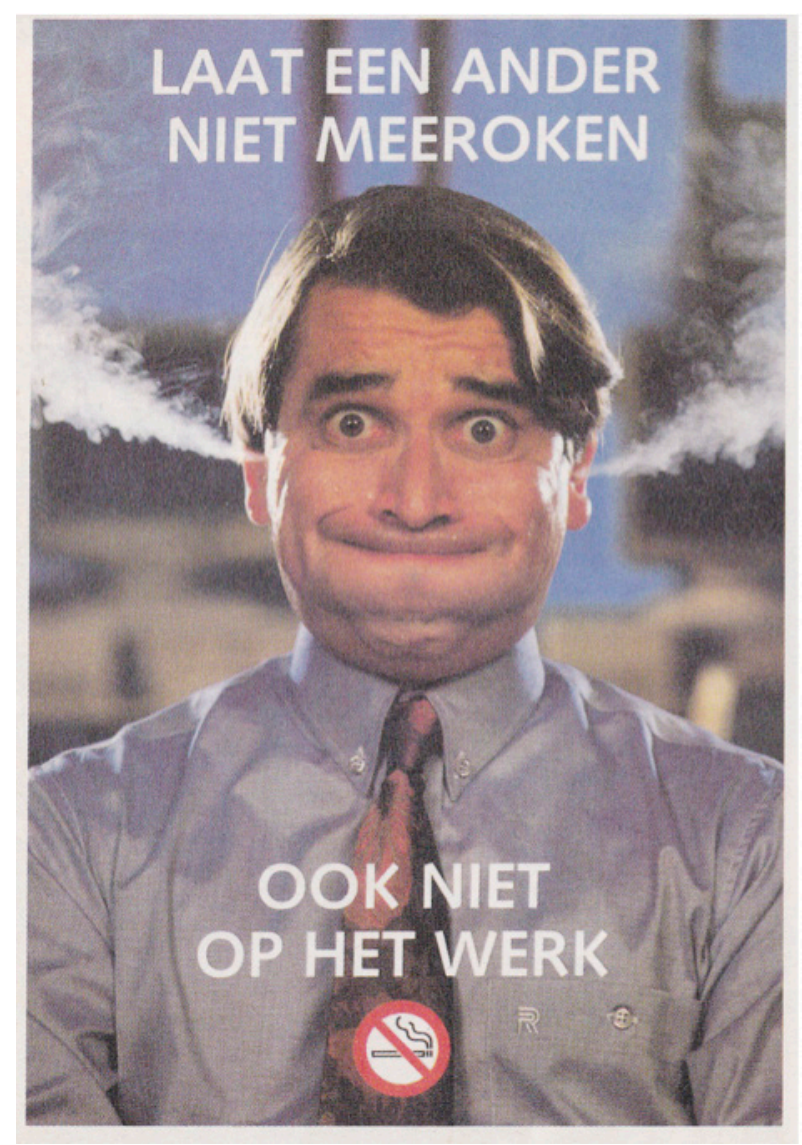

Afb. 4 Cover van een brochure voor reclame tegen meeroken op het werk, met beeld dat is afgeleid van de commercial voor de campagne.

Bron: Adformatie, 1990, nr. 49.

Ook in de vergelijking van de Nederlandse televisiereclame met het buitenland - een ander aspect dat in de vakpers regelmatig aan bod kwam - was de toon van de vertegenwoordigers van de reclamebureaus kritisch. De eerdergenoemde Beishuizen stelde, naar aanleiding van een bezoek aan een internationaal reclamefilmfestival in Venetië in 1970, dat de Nederlandse tv-reclame in technisch opzicht niet achterbleef bij andere landen. 'Wat betreft regie, cameravoering, montage, licht, geluid, kleur, opticals, behoorden onze inzendingen zeker niet tot de slechtste 
van de wereld.' De reden dat de Nederlandse inzendingen desalniettemin in Venetië vrijwel geen prijzen hadden behaald, was volgens Beishuizen 'waarschijnlijk, dat onze commercials, op zijn zachtst gezegd, nogal zwak zijn van ideeën. Het is, een paar uitzonderingen daargelaten, allemaal nogal onbeholpen, fantasieloos, en zonder enig raffinement. (....) Wij schijnen nog niet in staat te zijn om een idee goed uit te diepen, tot een script ontstaat waarin reclame en amusement elkaar niet tekort doen'.35 Met dit verwijt gaf Beishuizen ten dele blijk van zelfkritiek. Maar impliciet maakte hij ook duidelijk dat het zwaartepunt bij de verdere ontwikkeling van televisiereclame in Nederland, meer dan voorheen, bij de reclamebureaus diende te liggen. Van de productiemaatschappijen viel volgens hem op het terrein van creativiteit niets te verwachten, van de bureaus wel.

Vanaf begin jaren zeventig nam de aandacht voor de inhoud van televisiereclame en de rol van de reclamemaker vanuit professionele optiek, in de reclamevakpers af. Het aantal artikelen dat aan deze kwesties werd gewijd, liep terug. Een mogelijke verklaring daarvoor is dat, in het algemeen gesproken, de nieuwswaarde van het onderwerp televisiereclame, als facet van het vak van reclamemaker, minder werd. Daarnaast was er ook sprake van een verschuiving van de aandacht naar andere aspecten van televisiereclame. Vanaf circa I973 kwam de maatschappelijke kritiek op reclame in het brandpunt van de belangstelling te staan. Daar was volop reden toe. Bij het onderzoek Reclame en Publiek, dat in I973 werd uitgevoerd namens de Nederlandse Reclame Stichting, gaf 55 procent van de ondervraagde Nederlanders aan zich te ergeren aan tv-reclame; in een vergelijkbare enquête uit I969 kwam dat percentage nog uit op I7. ${ }^{36}$ De groeiende ergernis over (tv-) reclame werd daarmee ook een belangrijk onderwerp in de Nederlandse reclamevakpers.

In latere jaren zou de productiecultuur rondom de Nederlandse televisiereclame geleidelijk veranderen. Waar rond I970 de rol van het reclamebureau en de productiemaatschappij nog voer voor discussie was, werd de taakverdeling later duidelijk gescheiden. Het creatieve gedeelte - het bedenken van de reclamecampagne en het nader uitwerken van de ideeën voor de televisiecommercials - werd het domein van het reclamebureau, en de technische aspecten van de totstandkoming van tv-campagnes werden toebedeeld aan de productiemaatschappij. ${ }^{37}$

\section{Conclusie}

In dit artikel is aandacht besteed aan de wijze waarop reclamemakers in de beginjaren van de Nederlandse televisiereclame hun eigen professie beschouwden, met name aan de hand van artikelen in de Nederlandse reclamevakpers over de kenmerken en totstandkoming van televisiereclame. De jaargangen van de reclamevakbladen die hiervoor geanalyseerd zijn, laten een divers beeld zien. In de eerste jaren kreeg met name de effectiviteit van tv-reclame aandacht. Maar na verloop van tijd ebde de interesse daarvoor weg, en verschoof de belangstelling naar de kwaliteit van televisiereclame in meer algemene zin. In de artikelen die hieraan werden gewijd, werden termen gehanteerd als visuele aantrekkelijkheid, creativiteit, fantasie en idee: begrippen die zowel tot het cultureel-artistieke als tot het commerciële arsenaal kunnen worden gerekend. 

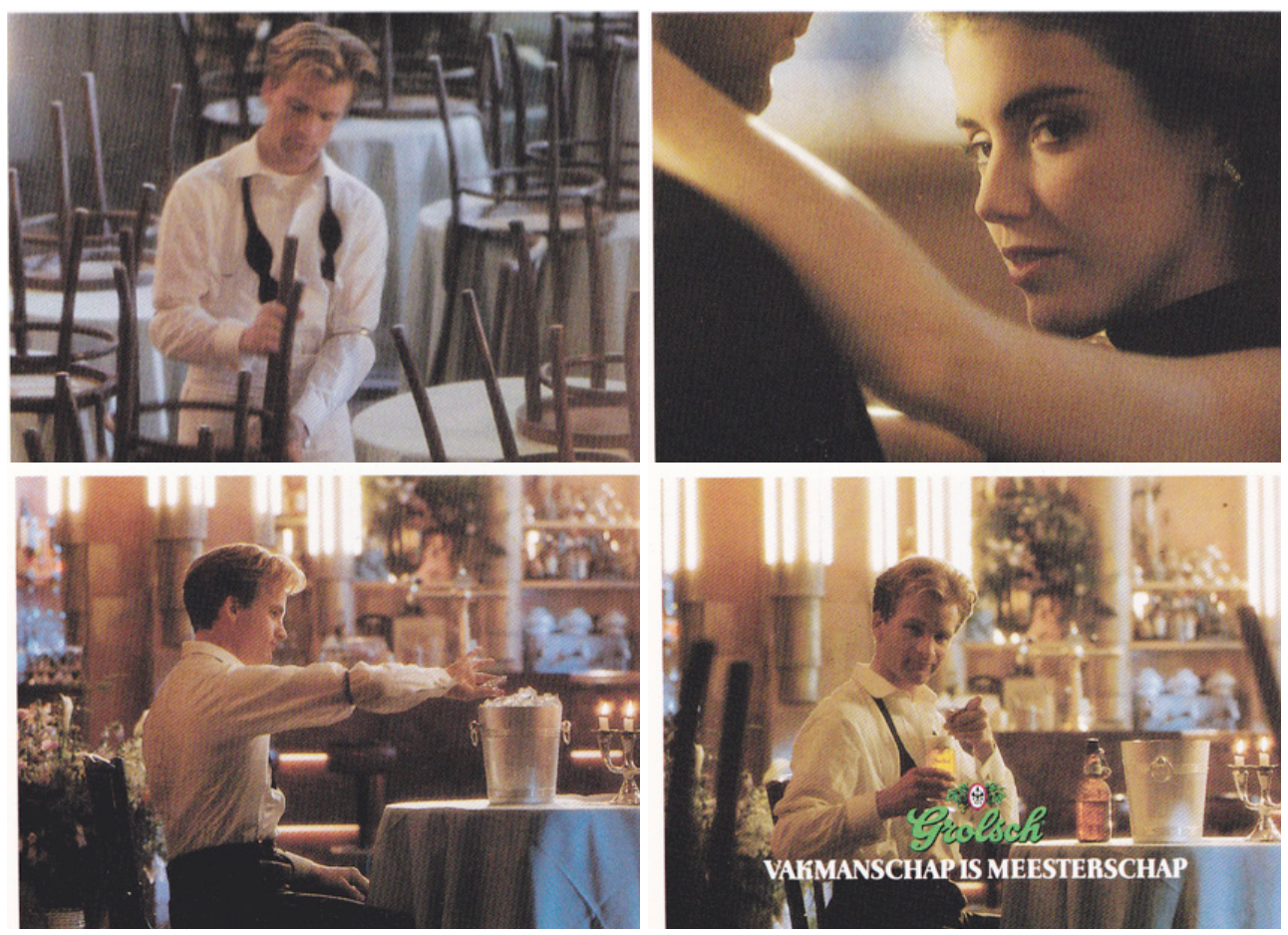

Afb. 5 Stills uit een commercial voor Grolsch uit 1989, geregisseerd door Will van der Vlugt.

Bron: brochure PPGH-JWT werk, 1989.

Het gebruik van dergelijke termen als criteria voor de beoordeling van tv-reclame maakt duidelijk dat, in de ogen van een deel van de reclamemakers, tv-commercials niet louter gericht moesten zijn op het duidelijk weergeven van de reclameboodschap, en dat er meer van de maker werd verwacht. En daarbij was enige culturele bagage geboden. De stelling van Leiss et al. dat reclamemakers 'have also attempted to turn their commercial canvas into something more than the crass selling of messages' lijkt in de beginfase van de Nederlandse televisiereclame ook voor de medewerkers van de reclamebureaus te gelden.

Maar betekent dit nu ook dat de Nederlandse reclamemakers die zich met televisiereclame bezighielden, de rol van cultureel intermediair vervulden, zoals Bourdieu die voor ogen had? Kunnen we zonder reserve stellen dat zij erop uit waren via de tv-reclame hun eigen culturele status te verhogen? Het zou te ver gaan om dit, op basis van het onderhavige onderzoek, te concluderen. Om te beginnen waren de opvattingen hierover te divers. De analyse van de artikelen in de reclamevakpers laat zien dat een deel van de reclamemakers meer belang hechtte aan de resultaatgerichtheid van tv-reclame dan aan de culturele dimensie. Daarnaast blijkt dat de visie die reclamemakers hadden op televisiereclame niet los gezien kan worden van de verhoudingen binnen de reclamebranche, en met name van de rivaliteit tussen productiemaatschappijen en reclamebureaus. Het lijkt erop dat de representanten van de reclamebureaus er indirect op uit waren hun opdrachtgevers ervan te overtuigen dat ze allereerst moesten vertrouwen op de inzichten en op de culturele 'voelsprieten' van het reclamebureau, en niet die van de productiemaatschappijen. De kanttekeningen van Nixon en Leiss et al. bij het gebruik van het etiket cultureel intermediair voor de reclamemaker zijn daarmee ook voor de Nederlandse situatie in de beginjaren van de tv-reclame van toepassing.

Daarbij moet opgemerkt worden dat de reclamevakpers een beperkt en deels gekleurd 
beeld geeft van de visies en uitlatingen van de reclamemakers. De reclamevakbladen zagen het mede als hun taak ertoe bij te dragen dat het reclamevak serieus genomen werd en maatschappelijk aanzien verwierf, en op basis daarvan ligt het voor de hand te veronderstellen dat men bij voorkeur reclamemensen aan het woord liet die erop uit waren het aanzien van en de waardering voor televisiereclame te verhogen.

Om een meer volledig beeld te krijgen van de visies van reclamemakers op tv-reclame en op hun eigen rol daarbij, is meer onderzoek nodig, met name in de archieven van productiemaatschappijen, reclamebureaus en opdrachtgevers. Vervolgonderzoek in deze richting zou een beter beeld kunnen geven van de achtergronden van degenen die bij de reclamebureaus en productiemaatschappijen betrokken waren bij de totstandkoming van tv-campagnes, en duidelijk maken in hoeverre bijvoorbeeld opleiding en de relatie met andere werkzaamheden mede bepalend was voor de culturele oriëntatie. Ook onderzoek naar verschillende van de begrippen die in dit artikel aan bod zijn gekomen, zou een nuttige aanvulling zijn. Een term als creativiteit, die vanaf de jaren zestig in de reclame in Nederland een steeds belangrijkere rol gaat spelen en door reclamebureaus in latere jaren zelfs gezien wordt als het onderscheidende kenmerk van hun werkzaamheden, vraagt om meer duiding. Wat werd hier door reclamemakers nu precies mee bedoeld, en hoe manifesteerde dit zich in de reclames die werden gemaakt? Kortom, er zijn op het gebied van de geschiedenis van televisiereclame nog tal van vragen die een nader onderzoek verdienen.

\section{Noten}

I. Zie voor een overzicht van de kritiek van academici op reclame in het algemeen, inclusief de kritiek op televisiereclame B. Richards, I. MacRury \& J. Botteril, The Dynamics of Advertising, Routledge, London 2000, p. 47-I00.

2. J.B. Twitchell, Adcult USA. The triumph of advertising in American culture, Columbia University Press, New York I996, p. 8-II.

3. Deze indeling is deels gebaseerd op de gangbare functies binnen de reclamebureaus in de periode, zoals die onder meer beschreven zijn in W. Schreurs, Geschiedenis van de Reclame in Nederland, Het Spectrum, Utrecht/Antwerpen 200I, p. 207-269 en in B. Kroon, TV Reclame Maken. Handwijzer voor televisiereclame in Nederland, J.H. de Bussy, Amsterdam i967, p. 9-I4.

4. Zie bijvoorbeeld B. Hogenkamp, S. de Leeuw en H. Wijfjes (red.), Een eeuw van beeld en geluid. Cultuurgeschiedenis van radio en televisie in Nederland, Nederlands Instituut voor Beeld en Geluid, Hilversum 20I2, en J. Bignell \& A. Fickers (eds), A European Television History, Wiley-Blackwell, Malden 2008.

5. Er zijn in de Verenigde Staten en Engeland wel diverse boeken verschenen over de geschiedenis van televisiereclame. Zie onder meer L.R. Samuel, Brought to you by. Postwar television and the American Dream, University of Texas Press, Austin 2003, en B. Henry (ed.), British television advertising. The first 30 years, Centry Benham Ltd., London I986.

6. Zie met name E. Cleven, Image bedeutet Bild. Eine Geschichte des Bildbegriffs in der Werbetheorie am Beispiel der Niederlande, 1917-1967, Utrecht I999, en R. van Rossum, Van advertentiekruier tot reclameadviesbureau: de ontwikkeling in Nederland, de Verenigde Staten en Duitsland voor de Tweede Wereldoorlog, Het Spinhuis, Apeldoorn 2012.

7. Zie bijvoorbeeld W. Schreurs, Leuker kunnen we 't niet maken: televisie- en radioreclame 1965-2005, STER, Hilversum 2004 .

8. J.T. Caldwell, Production culture. Industrial reflexivity and critical practice in film and television, Duke University Press, Durham 2008, p. 5-I4.

9. R. Marchand, Advertising the American Dream. Making Way for Modernity 1920-1940, University of California Press, Berkeley and Los Angeles I985, p. xxi. 
Io. W. Leiss, S. Kline, S. Jhally \& J. Botterill, Social Communication in Advertising: Consumption in the Mediated Marketplace, Routledge, London 2005 (3th ed.), p. 4I3.

II. Ibidem.

I2. De opvattingen hierover van Bourdieu zijn met name te vinden in zijn uit I979 daterende boek La distinction. Critique sociale du jugement. Voor dit artikel heb ik me vooral gebaseerd op de toelichting daarop in S. Nixon, Advertising Cultures. Gender, Commerce, Creativity, sage Publications Ltd, London-Thousand Oaks-New Delhi, 2003, p. 57-73, en Leiss et al., Social Communication, p. 303-306.

I3. Zie L. Edwards, 'Exploring the role of public relations as a cultural intermediair occupation', in: Cultural Sociology, I, vol. 4, 2012, p. 438-454, en J.R. Wynn, 'Guides through cultural work. A methodological framework for the study of cultural intermediairs', in: Cultural Sociology, I, vol. 4, 20I2, p. 336-350.

I4. Aidan Kelly, Katrina Lawlor \& Stephanie O’Donohoe, 'Encoding advertisements. The creative perspective', in: Journal of Marketing Management, 5, vol. 2I, juni 2005, p. 505-528.

15. Citaat bij Nixon, Advertising Cultures, p. 26.

I6. Nixon, Advertising Cultures, p. 68.

I7. Leiss et al., Social Communication, p. 413.

I8. Zie over de beginjaren van de Amerikaanse televisiereclame Samuel, Brought to you by, en over de vroege historie van de Britse televisiereclame Henry (ed.), British Television Advertising.

I9. Zie over de geschiedenis van de televisiereclame in Nederland onder meer G. Huiskes, E. Karel en R. van der Kroef, 25 Jaar Ster, een leeuw van een medium. Stichting Ether Reclame, Hilversum, I990; W. Schreurs, Leuker kunnen we 't niet maken, en H. Knot, 'Rumoer om de reclame. De moeizame invoering van de radio- en televisiereclame in Nederland (I95I-I967)’, in: Soundscapes, nr. 3, 2000, http://www.icce.rug.nl/ ^soundscapes/VOLUMEo3/Rumoer_ om_reclame.shtml (geraadpleegd op oI-IO-20I3).

20. Daarmee sluit ik me aan bij de visie van Marchand die stelt dat de reclamevakpers een uitstekende bron is om achter de schermen van de reclame-industrie te kijken omdat de artikelen daarin niet voor het algemene publiek werden geschreven maar voor (andere) professionals, en derhalve vaak 'with striking frankness the internal debates within the trade' weergeven; Marchand, Advertising the American Dream, p. 42I.

2I. De Revue der Reclame is een in I938 opgericht vakblad dat verscheen onder auspiciën van het Genootschap voor Reclame, een organisatie die zich tot taak had gesteld 'de ethische, esthetische en commerciële betekenis van de reclame en de erkenning daarvan' te bevorderen.

22. 'Deskundigen-discussie: wat was er goed aan tv-reclame in I967?', in: Revue der Reclame, maart I968, p. 94-95.

23. 'Komt boodschap goed door of niet? Experiment IPM-Y\&R-VB \& BV bewijst: commercials kunnen ook in stadium van pilotfilms goed worden ge-pretest', in: Revue der Reclame, april I967, p. 236-237, en J.W.S. Vervoort, 'Pre-testen van t.v.-commercials zegt niet alles. Televisie reclame-onderzoek moet het vooralsnog zonder deskundigen stellen’, in: Revue der Reclame, april ig67, p. 272-273.

24. 'Eerste ster-uitzending bewees: Reclamewereld kón de krant niet missen', in: Revue der Reclame, januari I967, p. I7-I8.

25. 'Vijf vragen aan vijf mensen', in: Revue der Reclame, februari I967, p. I64-I67.

26. C.J. Oerlemans, 'Creatieve start na I968 niet binnen bereik van iedere spotmaker', in: Revue der Reclame, februari ig68, p. 6I-62.

27. Henk van Gelder, 'Nederlandse tv-reclame heeft nu ook familieserie', in: Ariadne, I4 januari I970, p. 57-59.

28. F. van Lier, 'Van den Biggelaar presenteert morgen: vw-commercials zonder reclameboodschap', Ariadne, 4 februari I970, p. I79.

29. Zie onder meer L. Ripmeester, 'Entertainment uit de lage landen: de Geesink collectie', in: Tijdschrift voor Mediageschiedenis, vol. I5, I, 20I2, p. 74-IOI, en de ongepubliceerde memoires van Bert Kroon, 'When Californian Figs meet Macedonian Figs. Bericht over de prestaties van Nederlandse filmproducenten voor bioscoop- en televisiereclame in de tweede helft van de twintigste eeuw', 20II.

30. Kroon, 'When Californian Figs', p. 24.

31. Zo omschrijft Hogenkamp regisseur Ytzen Brusse als iemand die zich ontwikkelde 'tot wat men tegenwoordig een feel goed cineaste zou noemen, die bovendien sterk in de reclamerichting neigde'. B. Hogenkamp, De documentaire film 1945-1965. De bloei van een filmgenre in Nederland, о1о, Rotterdam 2003, p. II2.

32. Henk van Gelder, 'Sanering nodig in Nederlandse reclamefilmproduktie-industrie. Gesprek tussen producenten en bureaus dringend gewenst', in: Ariadne, 26 augustus I970, p. IIII.

33. Henk van Gelder, 'Het gaat om de mentaliteit. Waarom films maken in Engeland?', in: Ariadne, 30 december I970, p. I705.

34. Ibidem, p. I709. 
52 Tijdschrift voor Mediageschiedenis - I7 [I] 2OI4

35. M. Beishuizen, 'Amerikanen maken de beste commercials, wij zelf werken nog te onbeholpen', in: Ariadne, juli I970, p. 955 .

36. Zie Schreurs, Geschiedenis van de Reclame in Nederland, p. 256-259.

37. Zie voor voorbeelden onder meer de artikelen in Adformatie, jaargang 2006, over de making-of van diverse televisiecommercials, o.a.: S. van Nierop, 'The Making of Holland Casino', in: Adformatie, I9 oktober 2006, p. 20-23', en S. van Nierop, 'The Making of De Telefoongids', in: Adformatie, Io augustus 2006, p. 34-36'. 